\title{
Incidence of Chlamydia and Gonorrhoeae Infection among Patients at the Namibia Institute of Pathology
}

\author{
Shekupe Shivute ${ }^{1}$, Elizabeth I. Omodanisi ${ }^{2}$, Benjamin I. Okeleye ${ }^{2}$, Seteno K.O. Ntwampe ${ }^{2,3}$ and Yapo \\ G. Aboua ${ }^{1} *$
}

\begin{abstract}
Sexually Transmitted Infections (STIs) are associated with increased HIV transmission, infertility and other sexual health complications. This study aimed to determine the prevalence of chlamydia and gonorhoeae in people within the reproductive age referred to Namibia Institute of Pathology. A descriptive, retrospective cross sectional study was conducted to determine the prevalence of chlamydia and gonorrhoeae among 465 patients within the age group of $15-49$ years and covering 12 regions of Namibia. The urine sample was analyzed using Cepheid GeneXpert CT/NG. The overall prevalence of $12.7 \%$ and co-infection of $1.94 \%$, with adolescent within the age group of $15-19$ yrs were predominantly infected $(18.2 \%)$. Oshikoto region was mostly affected with the prevalence of $6.5 \%$ and only in women. Meanwhile, males were more affected than females in 7 regions with the marked prevalence of $3 \%$ in both Ohangwena and Khomas and $3.5 \%$ in Kavango East. In this study however, men were more positive to STIs $(14.5 \%)$ than women (11.6\%) in general; while the prevalence of $8.40 \%$ and $4.30 \%$ were recorded for $C$. trachomatis and $N$. gonorrhoeae respectively. Regular STIs screening and surveillance, using extra genital clinical samples is required for disease control purposes and prevention.
\end{abstract}

Keywords - Chlamydia; gonorrhoeae; prevalence; sexually transmitted infections

\section{INTRODUCTION}

Sexually Transmitted Infections (STIs) are spread predominantly by sexual contact namely vaginal, anal, and oral sex, with; more than thirty different bacteria, viruses and parasites known to be transmitted. Among the eight commonly accounted sexually transmitted pathogens, four are curable, such as; Syphilis, Gonorrhoeae, Chlamydia, and Trichomoniasis, meanwhile; the cures for the other four viral pathogens Hepatitis B, Herpes simplex virus (HSV), Human Immunodeficiency Virus (HIV), and Human papillomavirus (HPV) have not yet been found [1, 2]. It has been reported that gonorrhoeae have a growing threat of antibiotic resistance, and Namibia, like any other nations is facing a threatening major public health crisis that would result in significant reproductive

Manuscript received September 17, 2019.

${ }^{1}$ Department of Health Sciences, Faculty of Health and Applied Sciences, Private Bag 13388, Windhoek, Namibia; (S.S.)

${ }^{2}$ Bioresource Engineering Research Unit (BioERU), Department of Biotechnology, Faculty of Applied Sciences, Cape Peninsula University of Technology, P.O. Box 652, Cape Town 8000, South Africa;.

${ }^{3}$ Department of Chemical Engineering, Faculty of Engineering and the Built Environment, Cape Peninsula University of Technology, PO Box 1906, Bellville 7535, South Africa morbidity, including infertility [3, 4]. In 2010 Centers for Disease Control and Prevention (CDC) reported that the number one cause of mortality in Namibia is HIV, which could be associated with STIs as it facilitates HIV infection [5]. Chlamydia and gonorrhoeae are caused by an obligate, aerobic, gram-negative, dimorphic intracellular Chlamydia trachomatis (C. trachomatis) and a non-motile, non-spore-forming, gram-negative intracellular diplococci Neisseria gonorrhoeae ( N. gonorrhoeae) respectively. These pathogens are spread through unprotected sexual intercourse with an infected person. Nevertheless, they can also be transmitted from mother to child during vaginal childbirth. In women, chlamydial and gonococcal infections may cause pelvic inflammation, tubal infertility, chronic pelvic pain, and ectopic pregnancy. Chlamydial infection may also be linked to cervical cancer. Chlamydial and gonococcal infections may also increase the susceptibility of human immunodeficiency virus (HIV) in both men and women transmission [6].

C. trachomatis cause infection by their ability to attach and invade susceptible host cells, which are generally the columnar epithelial cells by the aid of two primary candidates; the major outer membrane protein (MOMP) and the chlamydial $60-\mathrm{kD}$ cysteine-rich protein $\mathrm{OmcB}$. They invade the host cell by phagocytosis, pinocytosis, or receptor-mediated endocytosis and internalized in membrane bound vacuoles transformed into reticulate bodies $(\mathrm{RBs})$ which are the metabolically active form $[7,8]$. About $60 \%-70 \%$ of infants exposed to C. trachomatis during vaginal childbirth acquire the infection, with conjunctivitis as the most frequent clinical manifestation in $15 \%$ - 37\% of exposed infants. C. trachomatis has an incubation period of 7 - 21 days with more than 50\%-infected males reported to be asymptomatic. The most common manifestation is urethritis and complications such as epididymitis and reactive arthritis may occur because of persistent infection. In females, chlamydia is reported to be the most common infection, and it commonly presents with cervicitis and urethritis. It is known to cause complications in females such as pelvic inflammatory disease (PID), which can lead to infertility, perihepatitis (Fitz-Hugh-Curtis syndrome), and reactive arthritis. Chlamydia causes trachoma in all ages, urogenital infection in both males and females, lymphogranuloma venerum (LGV), and pneumonia in neonates [2,9-11]. N. gonorrhoeae is the second most common bacterial sexually transmitted infection after $C$. trachomatis [4, 8, 11]. N. gonorrhoeae primarily infects columnar or cuboidal epithelium cells as it invades the mucous membrane of the contacted tissue and attaches to the microvillus 
of the epithelial cells. It is engulfed by the host cell's membrane endocytosis, which is mediated by lipo-oligosaccharide (LOS), and replicates through the endocytotic vacuoles that are formed [8]. Similar to Chlamydia, acute urethritis is the predominant manifestation of gonorrhoeae in men with initial symptoms of scant and mucoid urethral discharge and dysuria, usually without urinary frequency or urgency, while; within $1-2$ days it becomes overtly purulent. Acute epididymitis is the most common complication of urethral gonorrhoeae and rarely; penile lyphangitis, periurethral abscess, acute prostatitis, seminal vesiculitis, and infections of Tyson's and Cowper's glands $[2,8]$. N. gonorrhoeae affects the mucous membrane of the urethra, and the columnar epithelial cells that line the endocervix in women. About $80 \%$ of females with gonorrhoeae are asymptomatic, and it takes 10 days of infection to manifest in symptomatic patients. The dominant symptoms are increased vaginal discharge, dysuria often without urgency or frequency, and intermenstrual bleeding, sometimes triggered by coitus. Purulent discharge from the urethra or the ducts of Bartholin's glands may be observed. Ascending genital infection may occur with abdominal or pelvic pain, and it leads to PID the predominant complication and one of the most common causes of female infertility. Other complications are opthalmitis, disseminated infection with arthritis, dermatitis, and sometimes endocarditis $[4,8]$.

It has been projected that by the year 2040, the number of young people in Africa would have been increased by $60 \%$ [12] Health interventions targeted at this age group are important for current and future adult health and for the health of the next generation. This is particularly true for sexually transmitted infections (STIs), which when acquired in adolescence, can jeopardize sexual and reproductive health later in life and, for women, the health of their babies $[12,13]$. Namibia, with $66 \%$ of the population under the age of 30 and $39 \%$ below the age of 15 , requires comprehensive efforts to address youth health issues [3]. STIs, including the human immunodeficiency virus (HIV), are the most common cause of illness in Namibia, posing social and economic consequences. Reproductive age is different in men and women, since in women it is described as the years of life between menarche and menopause, roughly from ages 12 to 49 years. The term is imprecise, since some women can become pregnant and bear children at younger or older ages. In men, this is the year between the onset of puberty and loss of fertility [14]. Meanwhile, according to the World Health Organization, the reproductive age is $15-49$ years as it is derived from most of reported fertility studies for both women and men $[2,4]$. To the best of our knowledge, there is no recent data on the prevalence of chlamydia and gonorrhoeae among people within the reproductive age in Namibia; hence, this study sought to determine the prevalence of $C$. trachomatis and $N$. gonorrhoeae in patients referred and tested at Namibia Institute of Pathology (NIP) in 2017.

\section{MATERIALS AND METHODS}

\section{A. Study Design and Subjects}

This study was a descriptive, retrospective cross sectional investigation, which involved analysis of patients' laboratory records for the period of one year; January - December, 2017. We evaluated 465 patients within the age group of $15-49$, referred for chlamydia and gonorrhoeae examination, using nucleic acid amplification tests (NAATs) method at NIP-WRCL. Patients with no gender or age indicated were not included and the permission to carry out the study was granted by the Department of Medical Laboratory Health Sciences, Namibia University of Science, and Technology (NUST); Ministry of Health and Social Services (MoHSS) and by Namibia Institute of Pathology (NIP) [Protocol number 55-2018].

\section{B. Sampling and Data Collection Techniques}

Probability and convenience sampling methods were used; whereby, the records were stratified into two groups; age and sex for the selection of chlamydia and gonorrhoeae test results. The validity and reliability of the study was ensured by studying the maintenance, calibration, and quality control records of the equipment (Cepheid GeneXpert CT/NG) used for laboratory tests of urine samples in 2017. The sample size was estimated by means of Fisher's formula using the following equation:

$$
n=\frac{z^{2} p q}{d^{2}}
$$

Where:

$\mathrm{n}=$ minimum sample size

$\mathrm{z}=$ constant, standard normal deviation (1.96 for $95 \%$ confidence interval)

$\mathrm{p}=$ expected prevalence (the prevalence of chlamydia, gonorrhoeae, and co-infection in the reproductive age patients tested at NIP-WRCL is unknown, therefore $50 \%$ prevalence was assumed)

$\mathrm{d}=$ degree of accuracy desired usually set at 0.05

$\mathrm{q}=1-\mathrm{p}$

$\mathrm{z}=1.96$

$\mathrm{p}=0.5$

$\mathrm{q}=0.5$

The minimum sample size for the study was calculated with the confidence level of $95 \%$ and a confidence interval of 5\% used according to the method described by Kasiulevicius et al. [15].

\section{RESULTS}

\section{A. Analysis of the Study Population}

A total of 465 patients were enrolled and their mean age was 31.32 years (range $15-49$ years). Considering the age group, $30.97 \%(144 / 465)$ and $69.03 \%(321 / 465)$ were older and less than 35 years respectively. There were $172(36.99 \%)$ males and $293(63.01 \%)$ females (male/female ratio 1:1.7). Data collected was representing 12 geopolitical region of Namibia; namely, Erongo, Hardap, Karas, Kavango East, Kavango West, Khomas, Kunene, Ohangwena, Omusati, Oshana, Oshikoto and Zambezi. 


\section{B. Demographic distribution of C. trachomatis and N. gonorrhoeae}

Marked prevalence of C. trachomatis and N. gonorrhoeae was observed between the age group of $15-19,20-24$ and 25 - $29 \mathrm{yrs}$, with high percentage of $18.2 \%, 16.7 \%$ and $8.7 \%$ recorded in C. trachomatis than $9.1 \%, 8.3 \%$, and $6.4 \%$ in $N$. gonorrhoeae respectively. There was $6.7 \%$ of co-infection within the age group of $20-24$ yrs. There was a decrease in prevalence of $C$. trachomatis to $4.4 \%$ at the age group of $30-34$ yrs, which subsequently increased to $6.5 \%(35-39)$ and $6.8 \%$ $(40-44)$. The lowest percentage for both $C$. trachomatis and $N$. gonorrhoeae was $4.4 \%$ at the age group of $30-34$ and $45-49$ (Table I). Regarding gender, $21(7.2 \%)$ of the 293 enrolled females and $18(10.5 \%)$ of the 172 males were positive to $C$. trachomatis; while for $N$. gonorrhoeae, 13 (4.4\%) females and $7(4.1 \%)$ males were positive with co-infection of $1 \%$ and $3.5 \%$ respectively (Table I). STI was observed to be high in male than females between the age groups; $20-24,30-34,35-39,40-$ 44 and $45-49$ yrs with $4.7 \%$ (8/172), $3 \%(5 / 172), 1.2 \%$ (2/172), $1.2 \% \quad(2 / 172)$, and $0.6 \%$ (1/172) respectively. Meanwhile, it was high in female than in male only within age group of $15-19$ and $25-29$ yrs having percentage prevalence of $1.4 \%(4 / 293)$ and $4.8 \%$ (14/293). Noticeable prevalence was measured at the age groups of $20-24$ (male) and $25-29$ (female) yrs (Fig. 1). Of the 465 subjects, 39 had $C$. trachomatis-positive and $20 \mathrm{~N}$. gonorrhoeae-positive patients, giving the overall prevalence of $8.40 \%$ and $4.30 \%$ respectively. Meanwhile an overall STI prevalence of $12.7 \%$ (59/465) and co-infection of $1.94 \%(9 / 465)$ were observed, with more in men $(14.5 \%)$ than in women (11.6\%) [Table I and II].

Table I: PREVALENCE OF C. TRACHOMATIS AND N. GONORRHOEAE IN RELATION TO AGE GROUP AND GENDER

\begin{tabular}{|c|c|c|c|c|c|c|}
\hline Variables & $\begin{array}{c}\text { Study } \\
\text { subjects }\end{array}$ & $\begin{array}{c}C . \\
\text { trachomatis } \\
\text { +ve }(\%)\end{array}$ & $\begin{array}{c}C . \\
\text { trachomatis } \\
\text {-ve }(\%)\end{array}$ & $\begin{array}{c}N . \\
\text { gonorrhoeae } \\
\text { +ve }(\%)\end{array}$ & $\begin{array}{c}N . \\
\text { gonorrhoeae } \\
\text {-ve }(\%)\end{array}$ & $\begin{array}{c}\text { Co-infection } \\
(\%)\end{array}$ \\
\hline \multicolumn{7}{|l|}{ Age (yrs) } \\
\hline $15-19$ & 22 & $4(18.2)$ & $18(81.8)$ & $2(9.1)$ & $20(90.9)$ & $1(4.6)$ \\
\hline $20-24$ & 60 & $10(16.7)$ & $50(83.3)$ & $5(8.3)$ & 55 (91.7) & $4(6.7)$ \\
\hline $25-29$ & 126 & $11(8.7)$ & 115 (91.3) & $8(6.4)$ & $118(93.7)$ & $3(2.4)$ \\
\hline $30-34$ & 113 & $5(4.4)$ & $108(95.6)$ & $5(4.4)$ & $108(95.6)$ & $1(0.9)$ \\
\hline $35-39$ & 62 & $4(6.5)$ & 58 (93.6) & $0(00)$ & $0(00)$ & $0(00)$ \\
\hline $40-44$ & 59 & $4(6.8)$ & 55 (93.2) & $0(00)$ & $0(00)$ & $0(00)$ \\
\hline $45-49$ & 23 & $1(4.4)$ & $22(95.7)$ & $0(00)$ & $0(00)$ & $0(00)$ \\
\hline \multicolumn{7}{|l|}{ Gender } \\
\hline Male & 172 & $18(10.5)$ & $154(89.5)$ & $7(4.1)$ & $165(95.9)$ & $6(3.5)$ \\
\hline Female & 293 & $21(7.2)$ & 272 (92.8) & $13(4.4)$ & 280 (95.6) & $3(1)$ \\
\hline
\end{tabular}

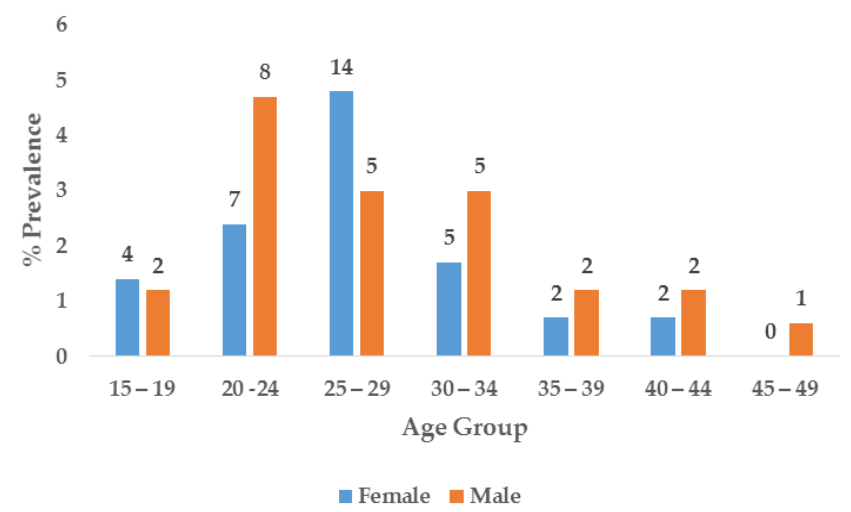

Fig. 1. Gender distribution of STIs within age group

Of the 12 regional location covered in this study, the prevalence of C. trachomatis and N. gonorrhoeae were high in 4 regions when compared to others. Marked prevalence of $1.94 \%$ (9/465) and 2.20\% (10/465) were observed in Oshikoto region for $C$. trachomatis and $N$. gonorrhoeae with co-infection of $1.10 \%$ (5/465). The prevalence of C. trachomatis in Kavango East and Khomas was 1.94\% (9/465), which is the same as that of the Oshikoto region. Five patients $(1.10 \%)$ were positive to C. trachomatis and $2(0.43 \%)$ to $N$. gonorrhoeae with only 1 $(0.22 \%)$ co-infected in Ohangwena region (Table II). The prevalence in Erongo, Kavango West, Oshana, Kunene, Omusati, Zambezi, Karas and Hardap regions was ranging between $0.22 \%(1 / 465)$ and $0.43 \%$ (2/465) for C. trachomatis and $N$. gonorrhoeae, which is very low when compared to others. Co-infection of $0.22 \%$ (1/465) was also noted in Erongo, Zambezi and Hardap regions despite the low prevalence recorded (Table II). Males were more affected than females in 7 regions; including Erongo, Kavango East, Khomas, Ohangwena, Zambezi, Karas and Hardap with marked prevalence of 3.5\% (6/172) in Kavango East, followed by 3\% $(5 / 172)$ in both Khomas and Ohangwena. Similar trend of $2.3 \%$ $(4 / 172)$ and $1.7 \%$ (3/172) was observed in Zambezi and Hardap. Moreover, a significant number of $19(6.5 \%)$ females were positive to STIs in Oshikoto with no infection observed in males (Fig. 2).

Table II: REGIONAL LOCATION AND THE PREVALENCE OF $C$. TRACHOMATIS AND N. GONORRHOEAE

\begin{tabular}{cccc}
\hline $\begin{array}{c}\text { Geographical } \\
\text { region }\end{array}$ & $\begin{array}{c}\boldsymbol{C} . \\
\text { trachomatis } \\
\text { +ve }(\%)\end{array}$ & $\begin{array}{c}\boldsymbol{N} . \\
\text { gonorrhoeae } \\
\text { +ve (\%) }\end{array}$ & $\begin{array}{c}\text { Co-infection } \\
(\%)\end{array}$ \\
\hline Erongo & $1(0.22)$ & $1(0.22)$ & $1(0.22)$ \\
Hardap & $2(0.43)$ & $1(0.22)$ & $1(0.22)$ \\
Karas & $1(0.22)$ & $0(00)$ & $0(00)$ \\
Kavango East & $9(1.94)$ & $0(00)$ & $0(00)$ \\
Kavango West & $0(00)$ & $1(0.22)$ & $0(00)$ \\
Khomas & $9(1.94)$ & $1(0.22)$ & $0(00)$ \\
Kunene & $0(00)$ & $1(0.22)$ & $0(00)$ \\
Ohangwena & $5(1.10)$ & $2(0.43)$ & $1(0.22)$ \\
Omusati & $0(00)$ & $1(0.22)$ & $0(00)$ \\
Oshana & $1(0.22)$ & $0(00)$ & $0(00)$ \\
Oshikoto & $9(1.94)$ & $10(2.20)$ & $5(1.10)$ \\
Zambezi & $2(0.43)$ & $2(0.43)$ & $1(0.22)$ \\
& $39(8.40)$ & $20(4.30)$ & $9(1.94)$ \\
\hline
\end{tabular}




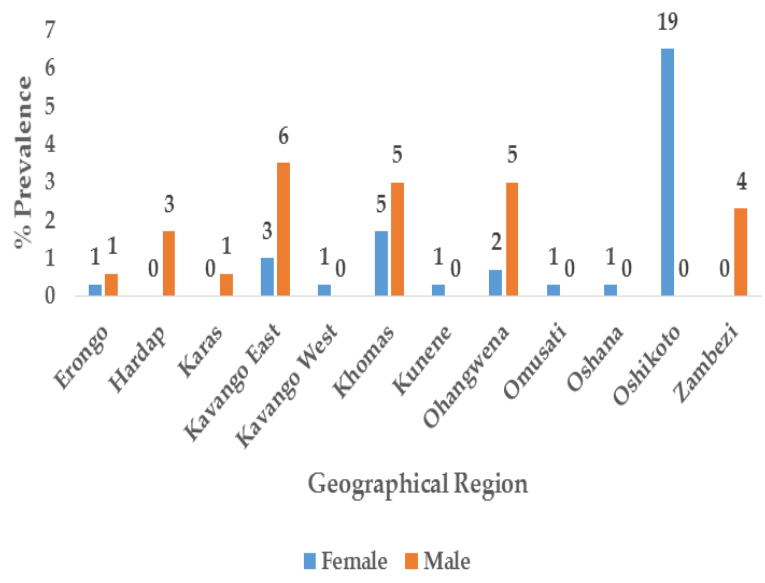

Fig. 2. Gender distribution of STIs across the region

The overall prevalence of STIs was therefore recorded as high with $4.1 \%$ in Oshikoto, followed by $2.2 \%, 1.9 \%$, and $1.5 \%$ in Khomas, Kavango East and Ohangwena respectively. The other 8 regions had prevalence of $0.2 \%$ for Kunene, Omusati, Karas, Oshana, Kavango East and 1.0\%, 0.7\%, 0.4\%, for Zambezi, Hardap and Erongo respectively (Fig. 3).

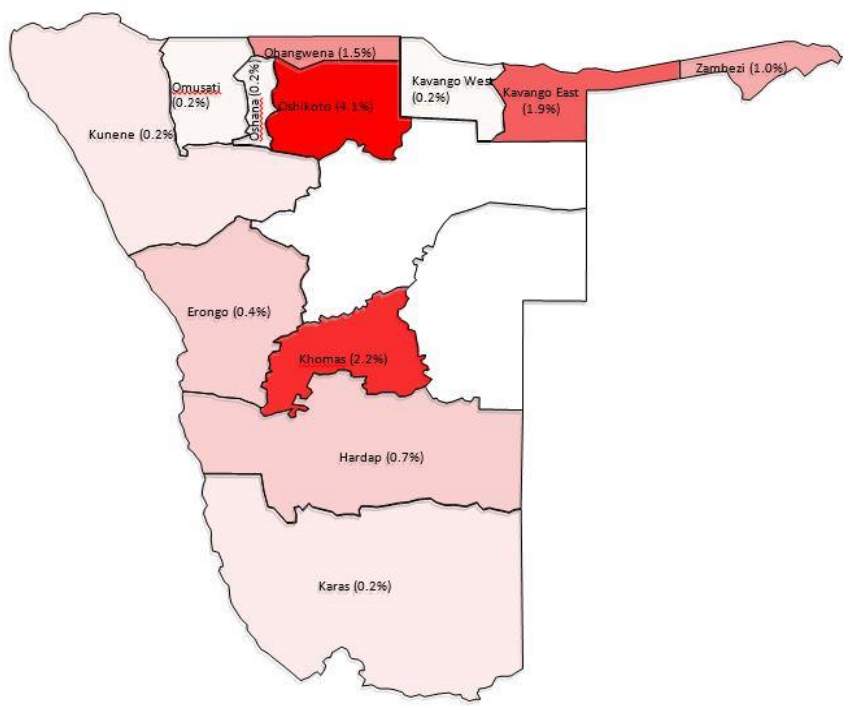

Fig. 3. Map of regional distribution of STIs

\section{DISCUSSION}

Sexually transmitted infections (STIs) caused by $N$. gonorrhoeae is on the increase, with practically 400,000 cases reported in the US in 2015 and epidemics were among young, black heterosexuals and men who have sex with men [16]. A recent projection revealed that Chlamydia trachomatis newly infected 50 million women worldwide, of which 34 million were in Africa and Asia. Chlamydial infection in women is commonly asymptomatic and when untreated can spread to genitalia, which may cause infertility, chronic pelvic pain, pelvic inflammatory disease (PID) and ectopic pregnancy [17]. This study determined the prevalence of chlamydia and gonorrhoeae in people within the reproductive age group $(15-49 \mathrm{yrs})$, tested at NIP in 2017. We recorded among females C. trachomatis' prevalence of $7.2 \%$ and in males $10.5 \%$ (Table 1). This is a lower prevalence when compared to a study conducted in Northern Nigeria where a prevalence of $26 \%$ was reported for $C$. trachomatis among women. High prevalence of $C$. trachomatis in this region has been linked with lack of use of condoms, low level of education, several sexual partners, early age marriage, and sexual intercourse [18]. In USA $60 \%$ of non-Hispanic black women were reported to be infected with $C$. trachomatis which is 5 times more than in non-Hispanic whites with chlamydia-associated tubal factor infertility [13]. Meanwhile, in China $4.12 \%$ of women with associated demographic (e.g., ethnic minority) and behavioral risk factors were reported to be infected with $C$. trachomatis [19]. Overall $8.40 \%$ and $4.30 \%$ (Table 1 and 2) of participants were positive for C. trachomatis and N. gonorrhoeae respectively. Studies have shown that the prevalence of $C$. trachomatis is usually higher than that of $N$. gonorrhoeae and $C$. trachomatis' prevalence similar in men having sex with men when compared with prevalence in women, whereas $N$. gonorrhoeae prevalence is higher in men having sex with men than in women [19-21]. In this study $4.1 \%$ of male and $4.4 \%$, females were positive to $N$. gonorrhoeae in Namibia (Table 1). South Africa using Spectrum-STI tool has estimated in female and male between 1990 and 2017, the prevalence of $6.6 \%$ and $3.5 \%$ for $N$. gonorrhoeae and for chlamydia $14.7 \%$ and $6.0 \%$ respectively. High rates of STIs and antimicrobial resistant in gonorrhoeae have prompted South Africa to conduct a national STI estimation of trends in the population burden of antimicrobial resistant gonorrhoeae [22].

A high prevalence of STIs was mostly found in rural setting or an area of ethnic minority group, among the adolescent and in an area with high HIV prevalence. It has been projected that by 2040, the number of youth in Africa would have increased by $60 \%$ to more than 466 million [19, 23]. High prevalence of $C$. trachomatis and $N$. gonorrhoeae observed within the reproductive age group of $15-19(18.2 \%, 9.1 \%), 20$ - $24(16.7 \%, 8.3 \%)$, and $25-29(8.7 \%, 6.4 \%)$ [Table 1] corroborates the findings reported in South Africa with the estimated range of $8.0 \%-20.6 \%$ for chlamydia, $1.4 \%-8.9 \%$ for gonorrhoeae among the youth within the age group of 15-19 and 20-24 yrs [23]. This may be because, at this age group, the individuals become sexually active and engage in risky contributing factors for contracting the disease. Adolescents tend to be at a higher risk of contracting STIs due to unawareness of preventive methods and it can also be biologically related to the columnar epithelial cells on the ectocervix, known as the ectopy, which is more common in female adolescents, and it is known to increase susceptibility to infection [11, 24]. C. trachomatis interchanges between two morphological forms, the elementary body (EB) and the reticulate body (RB). Elementary bodies (EBs) are extra-cellular, the infectious particles found in secretions and they are metabolically inert. Within eight hours, they transform into reticulate bodies (RBs) which are the metabolically active form. RBs undergo repeated cycles of binary fission leading to secondary differentiation back to EBs within 24 hours. In 48 72 hours, the inclusion matures and the cell lysed to release infectious EBs. Released elementary bodies attach and invade 
other neighboring cells or are transmitted to another individual and cause an infection [9]. This process induces a strong immune response that can result in damage and scarring to the infected site [7, 8, 11]. Endocytotic vacuoles formed by host cell's membrane in which $N$. gonorrhoeae can replicate; transport the bacterium to the bottom membrane of the host cell and with time, the infected membrane dies; hence the release of accumulated bacterium into sub-epithelial space which disarm the complement system for survival in the host $[8,10,11]$. Health mediations directed towards this age group are essential for current and future adult health and that of the next generation. STIs, when developed in youth, can endanger sexual and reproductive health later in life and that of their children. High STI prevalence among adolescent has been observed worldwide which places an interest on the serious need for inclusive efforts to advance sexual and reproductive health among this age group [23].

Namibia is a huge country with 824116 square kilometres of geographical area, but one of the smallest countries in Africa when it comes to its population size of about 2.1 million. Like many other African countries, Namibia emerged from suppression under apartheid, which resulted in extremely entrenched levels of inequality and poverty [3]. The prevalence of STIs was high in Oshikoto and Khomas region of Namibia than others with $4.1 \%$ and $2.2 \%$ respectively (Table 2 and Figure 3). Oshikoto region also had the highest co-infection rate of $1.10 \%$ and a marked STIs prevalence of $6.5 \%$ observed only in females (Table 2 and Figure 2). C. trachomatis and $N$. gonorrhoeae were both common in Oshikoto region while only C. trachomatis was predominant infection in Khomas and Kavango East region and more in males than in females (Table 2 and Figure 2). High prevalence among women in Oshikoto region could be associated with the anatomy of females' reproductive tract, which makes it more possible to acquire an STI. The vagina has a thin lining and it is delicate compared to the skin on a penis; hence easier for bacteria to penetrate. In addition, the vagina is a good environment for bacteria, because of its moist and favorable $\mathrm{pH}$ for bacterial growth [24]. Moreover, it could be associated with oral contraceptives, that may increase the cervical ectopy and this makes one susceptible to STIs [8]. Guy et al. [25] reported in Australia similar rate in women $(2.0 \%)$ and men $(4.1 \%)$ of $C$. trachomatis and $N$. gonorrhoeae co-infection among 16 - 19 yrs reproductive age group. A higher prevalence could be associated with a higher sample size used for the study, or it could be that there is a high rate of infection with contributing factors such as culture, level of education and socio-economic status. STI is more prevalent in men than in women in Namibia as we recorded $14.5 \%$ for male and $11.6 \%$ in females as well as high co-infection of $6.7 \%$ in males' within the reproductive age group of $20-24$ yrs than female (Table 1). This could be because males may present with symptoms after an infection unlike females who could be asymptomatic. Omusati, Oshana, Kunene, and Kavango west regions had $1(0.22 \%)$ case of STI per region and only in females (Table 2 and Figure 2). This could be associated with high rates of pregnancy in these regions or cultural reasons such as early marriage. Hardap, Zambezi, and Karas regions had cases of STIs infection in males with no female infection observed which could be related to females being asymptomatic or a possibility of men who have sex with other men [20].

Oshikoto is one of the fourteen regions of Namibia and the northern part of the region is largely into agriculture, especially the growing of pearl millet crop, while the main economic activities in the southern part are cattle rearing and mining. Meanwhile, Oshikoto is one of the three regions without either a shoreline or a foreign border. Although the mining may have a limited life span, it can support and boost industrial activities and services. This is comparable to Khomas region, which is at the center of capital city Windhoek, the second region with high prevalence of STIs in this study. Oshikoto region is similar to Mwanza region in Tanzania, which was described by Changalucha et al. [26] as a rural population that lives mostly on subsistence farming; mainly of cotton, maize, and fishing farming with some gold mining activities in the western part of the region. The engagement of foreign companies in the gold mining and the associated developments are likely to bring about major changes in terms of demography, economics, and STIs. These may be some of the contributing factors to the high prevalence of STIs observed in Oshikoto region among women. Even though the minimum sample size was reached, this study may not fully represent the reproductive population of Namibia as there were months when data was not available as well as the fact that only urine sample was collected for analysis and not all regions were represented in this study. Regular surveillance may be necessary for a period of $3-7$ years of study, covering all regions and the use of $2-3$ specimens or samples for analysis.

\section{CONCLUSION}

The prevalence of STIs is on the rise in Namibia as this study showed an overall prevalence of $12.7 \%$, with co-infection of $1.94 \%$ in the year 2017. Adolescent with the age group of 15 -19 yrs were predominantly infected $(18.2 \%)$. Young people in general, and especially women in Oshikoto region may need special attention from the public health agency, as the infection was high in women of that region (6.5\%). More men (14.5\%) were affected than in women (11.6\%); meanwhile, $C$. trachomatis $(8.40 \%)$ was more in circulation than $N$. gonorrhoeae $(4.30 \%)$. Sexual health education and the screening of all sexually active people, using in addition extra genital specimens especially when symptomatic, as well as the screening and testing of the rectal and pharyngeal specimens in men who have sex with other men even when asymptomatic is important in order to prevent and control STIs. Routine rescreening and treatment of positive patients' sex partners, appropriate diagnostic testing in people with compatible clinical syndromes, adherence to recommended treatment regimens, periodic testing of isolates to monitor trends in antimicrobial resistance, routine testing for other common infection in all people with a newly acquired sexually transmitted disease, administration of systemic antibiotics immediately before or soon after sexual exposure and public education and awareness campaigns on STIs are essential and recommended. This study might help to explain the differences in STI prevalence at regional level where increased efforts are needed to control the burden of $C$. trachomatis and $N$. gonorrhoeae infections. Insight into the mechanisms that drive the burden of these 
infections is essential for disease control. Hence, the study outcomes can have important implications on developing rationale measures to effectively detect and manage STIs. Results may be used for awareness campaign, policy, and program development.

\section{ACKNOWLEDGMENT}

We thank the staffs of Namibia Institute of Pathology for their technical assistant.

\section{REFERENCES}

[1] L. Newman, J. Rowley, S. Vander Hoorn, N. S. Wijesooriya, M. Unemo, N. Low, G. Stevens, S. Gottlieb, J. Kiarie, and M. Temmerman, "Global estimates of the prevalence and incidence of four curable sexually transmitted infections in 2012 based on systematic review and global reporting," PLoS One, vol. 10, no. 12, pp. 1-17, Dec. 2015. https://doi.org/10.1371/journal.pone.0143304

[2] WHO guidelines for the treatment of Chlamydia trachomatis, World Health Organization, Geneva, Switzerland, 2016, pp. 1-44.

[3] P. Chiwara, and A. Lombard, "The challenge to promote social and economic equality in Namibia through social work," Soc. work, vol. 53, no. 4, pp. 562-578, Nov. 2017. https://doi.org/10.15270/53-4-598

[4] WHO guidelines for the treatment of Neisseria gonorrhoeae, World Health Organization, Geneva, Switzerland, 2016, pp. 1-50.

[5] Namibia Health Facility Census 2009: Key Findings on HIV/AIDS and STIs, Ministry of Health and Social Services (MoHSS) [Namibia] and ICF Macro, Windhoek, Namibia, 2010, pp. 1-24.

[6] W. C. Miller, C. A. Ford, M. Morris, M. S. Handcock, J. L. Schmitz, M. M. Hobbs, M. S. Cohen, K. M. Harris, and J. R. Udry, "Prevalence of chlamydial and gonococcal infections among young adults in the United States," Jama, vol. 291, no. 18, pp. 2229-2236, May 2004. https://doi.org/10.1001/jama.291.18.2229

[7] Y. M. AbdelRahman, and R. J. Belland, "The chlamydial developmental cycle," FEMS Microbiol. Rev., vol. 29, no. 5, pp. 949-959, Nov. 2005.

https://doi.org/10.1016/j.femsre.2005.03.002

[8] G. Mandell, J. Bennett, and R. Dolin, "Principles and practice of infectious diseases," 7th ed. vol. 1, Philadelphia, PA: Elsevier, 2010, pp. 1-4019.

[9] J. J. Chang, K. R. Leonard, and Y. X. Zhang, "Structural studies of the surface projections of Chlamydia trachomatis by electron microscopy," J. Med. Microbiol, vol. 46, no. 12, pp. 1013-1018, Dec. 1997.

https://doi.org/10.1099/00222615-46-12-1013

[10] R. P. Peters, J. H. Dubbink, L. van der Eem, S. P. Verweij, M. L. Bos, S. Ouburg, D. A. Lewis, H. Struthers, J. A. Mclntyre, and S. A. Morré, "Cross-sectional study of genital, rectal, and pharyngeal Chlamydia and gonorrhea in women in rural South Africa," Sexual. Trans. Dis., vol. 41, no. 9, pp. 564-569, Sept. 2014. https://doi.org/10.1097/OLQ.0000000000000175

[11] Sexually Transmitted Disease Surveillance, Centers for Disease Control and Prevention, U.S. Department of Health and Human Services, Atlanta, Ga, USA, 2015, pp. 1-137.

[12] World population monitoring, adolescents and youth: A Concise Report. Department of Economic and Social Affairs, Population Division, New York: United Nations, 2012, pp. 1-56.

[13] L. C. Chambers, C. M. Khosropour, D. A. Katz, J. C. Dombrowski, L. E. Manhart, and M. R. Golden, "Racial/ethnic disparities in the lifetime risk of Chlamydia trachomatis diagnosis and adverse reproductive health outcomes among women in King County, Washington," Clin. Infect. Dis., vol. 67, no. 4, pp. 593-599, Aug. 2018.

https://doi.org/10.1093/cid/ciy099

[14] Mosby, "Mosby's medical dictionary," 9th ed., St. Louis, MO: Mosby Elsevier, 2012, pp. 1-1984.
[15] V. Kasiulevičius, V. Šapoka, and R. Filipavičiūtè, "'Sample size calculation in epidemiological studies," Gerontol., vol. 7, no. 4, pp. 225-231, Sept. 2006.

[16] A. R. Tuite, M. M. Rönn, E. E. Wolf, T. L. Gift, H. W. Chesson, A. Berruti, K. Galer, N. A. Menzies, K. Hsu, and J. A. Salomon, "Estimated impact of screening on gonorrhea epidemiology in the united states: insights from a mathematical model," Sexual. Trans. Dis., vol. 45, no. 11, pp. 713-722, Nov. 2018. https://doi.org/10.1097/OLQ.0000000000000876

[17] S. Hussen, D. Wachamo, Z. Yohannes, and E. Tadesse, "Prevalence of Chlamydia trachomatis infection among reproductive age women in sub Saharan Africa: a systematic review and meta-analysis," $B M C$ Infect. Dis., vol. 18, no. 1, pp. 1-8, Nov. 2018.

https://doi.org/10.1186/s12879-018-3477-y

[18] O. T. Ige, S. O. Ige, and A. T. Olayinka, "Prevalence of Chlamydia trachomatis infection among women of reproductive age group in a tertiary hospital in Northern Nigeria," Ann. Trop. Pathol., vol. 9, no. 1, pp. 17-21, Sept. 2018. https://doi.org/10.4103/atp.atp_35_17

[19] Z. Z. Luo, W. Li, Q. H. Wu, L. Zhang, L. S. Tian, L. L. Liu, Y. Ding, J. Yuan, Z. W. Chen, L. N. Lan, X. B. Wu, Y. M. Cai, F. C. Hong, T. J. Feng, M. Zhang, and X. S. Chen "Population-based study of chlamydial and gonococcal infections among women in Shenzhen, China: Implications for programme planning," PLoS One, vol. 13, no. 5, pp. 1-11, May 2018. https://doi.org/10.1371/journal.pone.0199907

[20] S. R. Leon, E. R. Segura, K. A. Konda, J. A. Flores, A. Silva-Santisteban, J. T. Galea, T. J. Coates, J. D. Klausner, and C. F. Caceres, "High prevalence of Chlamydia trachomatis and Neisseria gonorrhoeae infections in anal and pharyngeal sites among a community-based sample of men who have sex with men and transgender women in Lima, Peru," BMJ Open, vol. 6, pp. 1-9, Jan. 2016.

https://doi.org/10.1136/bmjopen-2015-008245

[21] C. M. Dewart, K. T. Bernstein, N. P. DeGroote, R. Romaguera, and A. N. Turner, "Prevalence of rectal chlamydial and gonococcal infections: a systematic review," Sexual. Trans. Dis., vol. 45, no. 5, pp. 287-293, May 2018.

https://doi.org/10.1097/OLQ.0000000000000754

[22] R. S. Kularatne, R. Niit, J. Rowley, T. KufaChakezha, R. P. H. Peters, and M. M. Taylor, "Adult gonorrhea, chlamydia and syphilis prevalence, incidence, treatment and syndromic case reporting in South Africa: Estimates using the Spectrum-STI model, 1990-2017," PLoS One, vol. 13, no. 10, pp. 1-22, Oct. 2018. https://doi.org/10.1371/journal.pone.0205863

[23] S. C. Francis, T. N. Mthiyane, K. Baisley, S. L. Mchunu, J. B. Ferguson, T. Smit, T. Crucitti, D. Gareta, S. Dlamini, T. Mutevedzi, J. Seeley, D. Pillay, N. McGrath, and M. Shahmanesh, "Prevalence of sexually transmitted infections among young people in South Africa: A nested survey in a health and demographic surveillance site," PLoS Med., vol. 15, no. 2, pp. 1-25, Feb. 2018.

https://doi.org/10.1371/journal.pmed.1002512

[24] K. C. Chinsembu, "Sexually transmitted infections in adolescents," The Open Infect. Dis. J., vol. 3, no. 1, pp. 107-117, Aug. 2009. https://doi.org/10.2174/1874279301004010107

[25] R. Guy, J. Ward, H. Wand, A. Rumbold, L. Garton, B. Hengel, B. Silver, D. Taylor-Thomson, J. Knox, S. McGregor, A. Dyda, C. Fairley, L. Maher, B. Donovan, and J. Kaldor "Coinfection with Chlamydia trachomatis, Neisseria gonorrhoeae and Trichomonas vaginalis: a cross-sectional analysis of positivity and risk factors in remote Australian Aboriginal communities," Sexual. Trans. Infect., vol. 91, no. 3, pp. 201-206, May 2015.

https://doi.org/10.1136/sextrans-2014-051535

[26] J. Changalucha, A. Gavyole, H. Grosskurth, R. Hayes, and D. Mabey, "STD/HIV intervention and research programme Mwanza Region, NW Tanzania," Sexual. Trans. Infect., vol. 78, no. 1, pp. 91-96, Nov. 2002.

https://doi.org/10.1136/sti.78.suppl_1.i91 


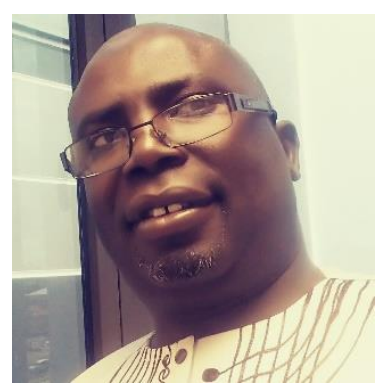

Dr Yapo G Aboua is currently coordinating the Master and the $\mathrm{PhD}$ programmes in Health Sciences in the Faculty of Health and Applied Sciences at Namibia University of Science and Technology. His Research area is Reproductive Biology and is actively involve in Child, Maternal and

Reproductive Health Research. With more than 10 years of research experience, Dr Aboua supervised up to 19 (Hons and B.Tech), 19 Masters and $8 \mathrm{PhD}$ and examined 16 (Hons and B. Tech), 6 Masters and $3 \mathrm{PhD}$ theses. He published more than 45 articles; 11 book chapters, attended more than 35 conferences. Dr Aboua is a reviewer and Editorial Board Member of number of Journals. Dr Aboua received numerous awards for his research. 